\title{
The Mechanical Properties of a Poly(methyl methacrylate) Denture Base Material Modified with Dimethyl Itaconate and Di-n-butyl Itaconate
}

\author{
Pavle Spasojevic, ${ }^{1}$ Milorad Zrilic, ${ }^{2}$ Vesna Panic, ${ }^{1}$ Dragoslav Stamenkovic, ${ }^{3}$ \\ Sanja Seslija, ${ }^{4}$ and Sava Velickovic ${ }^{2}$ \\ ${ }^{1}$ Innovation Center of the Faculty of Technology and Metallurgy, University of Belgrade, 4 Karnegijeva Street, 11000 Belgrade, Serbia \\ ${ }^{2}$ Faculty of Technology and Metallurgy, University of Belgrade, 4 Karnegijeva Street, 11000 Belgrade, Serbia \\ ${ }^{3}$ Faculty of Dentistry, University of Belgrade, 8 Dr. Subotića Street, 11000 Belgrade, Serbia \\ ${ }^{4}$ Institute of Chemistry, Technology and Metallurgy, University of Belgrade, 12 Njegoseva Street, 11000 Belgrade, Serbia \\ Correspondence should be addressed to Pavle Spasojevic; pspasojevic@tmf.bg.ac.rs
}

Received 24 February 2015; Revised 17 May 2015; Accepted 18 May 2015

Academic Editor: Huining Xiao

Copyright (C) 2015 Pavle Spasojevic et al. This is an open access article distributed under the Creative Commons Attribution License, which permits unrestricted use, distribution, and reproduction in any medium, provided the original work is properly cited.

\begin{abstract}
This study investigates a wide range of clinically relevant mechanical properties of poly(methyl methacrylate) (PMMA) denture base materials modified with di-methyl itaconate (DMI) and di- $n$-butyl itaconate (DBI) in order to compare them to a commercial PMMA denture base material. The commercial denture base formulation was modified with DMI and DBI by replacing up to $10 \mathrm{wt} \%$ of methyl methacrylate (MMA) monomer. The specimens were prepared by standard bath curing process. The influence of the itaconate content on hardness, impact strength, tensile, and thermal and dynamic mechanical properties was investigated. It is found that the addition of di- $n$-alkyl itaconates gives homogenous blends that show decreased glass transition temperature, as well as decrease in storage modulus, ultimate tensile strength, and impact fracture resistance with increase in the itaconate content. The mean values of surface hardness show no significant change with the addition of itaconates. The magnitude of the measured values indicates that the poly(methyl methacrylate) (PMMA) denture base material modified with itaconates could be developed into a less toxic, more environmentally and patient friendly product than commercial pure PMMA denture base material.
\end{abstract}

\section{Introduction}

One of the most important unmodified acrylic materials for dental applications is poly(methyl methacrylate) (PMMA). Discovered and commercialized many years ago, PMMA is one of the most widely used industrial polymeric materials and still remains an active material for research at the cutting edges of science. Because of its good biocompatibility, reliability, dimensional stability, absence of taste, odor, tissue irritation and toxicity [1], teeth adhesion [2], insolubility in body fluids, relative ease of manipulation, good aesthetic appearance [3], and color stability [4], PMMA based materials are widely used as biomaterials. Nowadays, PMMA finds applications not only in dentistry but also in areas such as transparent glass substitutes, interior design, transparent dielectric films [5], acrylic paints [6], and microcellular foams
[7]. Still, one of the most attractive applications of PMMA based materials is in various biomedical applications such as intraocular lenses [8], bone cement in orthopedic surgery [9], and removable partial denture [10].

Although PMMA denture base materials have a lot of qualities, they are often subject to intense criticism because of their inherent drawbacks such as residual monomer toxicity and its effect on the oral tissues (Figure 1) [11-15], mechanical properties that are not always perfect [16], and susceptibility to distortion. The cumulative effect of these properties may lead to residual monomer leakage into adjacent oral tissues and the generation of cracks and the other structural damage of denture base that, apart from leading to denture base breakage, can also form a point of entry for various bacteria, yeasts, and moulds. 

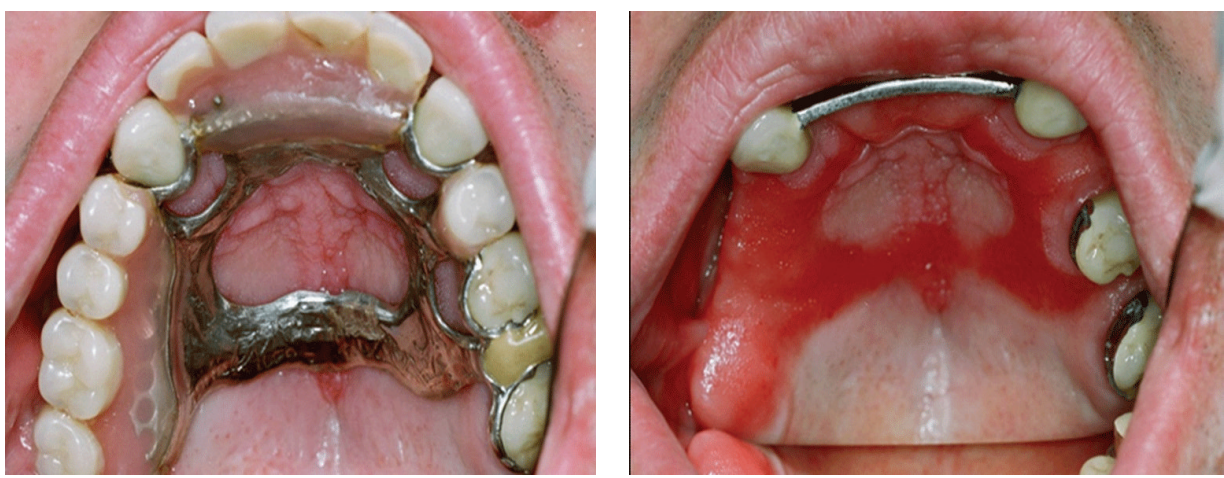

FIGURE 1: Inflammation of the oral mucosal tissues after removal of the prosthesis.

In order to overcome the drawbacks of pure PMMA denture base material we have investigated the possibility of modifying the commercial formulations with the derivatives of itaconic acid. The similarity of di-itaconates and corresponding methacrylates makes polymers based on itaconic acid an interesting alternative to the methacrylic acid based materials. The advantage of itaconic over methacrylic acid is the fact that the itaconic acid is a natural product, and its industrial sized production is based on renewable resources $[17,18]$ rendering it significantly less toxic [19]. The replacement of methacrylates, partly or completely, results also in significantly less toxic residual monomer, which in turn would not cause the inflammation of the tissue that comes into contact with the denture. As a dibasic acid, itaconic acid gives a larger scope of possible ester substituents than methacrylic acid. Itaconic acid derivatives are cocomponents in various formulations in controlled-drug release systems [20-24], paints and coatings [25-27], resist compositions [28, 29], contact lenses [30] ocular lenses [31], and personal care compositions [32]. In dentistry, itaconic acid and itaconates have been used in glass-ionomer cements [33-35].

The copolymers of methyl methacrylate and dialkyl itaconates have been investigated in many studies because of their structural similarity. The kinetics of copolymerization has been thoroughly examined [36, 37]. Fernández-García and Madruga examined the influence of copolymer composition on the glass transition temperature [38]. They have come to the conclusion that the glass transition temperature of copolymer decreased with the increase in the amount of itaconates in the copolymer as well as in the chain length of ester alkyl groups. The same authors have examined the thermal stability of methyl methacrylate copolymers with dialkyl itaconates and found that the relative thermal stability increased with the increase in methyl methacrylate copolymer molar fraction, following a trend similar to the glass transition temperature variation [39].

In our previous study we have investigated water sorption and residual monomer content in the PMMA denture base materials modified with DMI and DBI [40]. We have found that addition of itaconates reduced water sorption and greatly decreased residual MMA content. The highest reduction was for the material where MMA was replaced by $10 \mathrm{wt} \%$ of DMI and reduction was $88 \%$ while in the other cases the reduction ranged from $49 \%$ to $84 \%$. As residual MMA has been recognized as the main cause of allergic sensitization, contact dermatitis, and tissue inflammation, its reduction significantly improved the applicative properties and biocompatibility of the PMMA denture base material. It gave us a reason to continue investigation of such materials.

To the best of our knowledge, there are no literature data that evaluate mechanical properties of copolymers of dialkyl itaconates and methyl methacrylate. Taken that it is not only the lesser toxicity and the "greener" properties of the material that are important for the enhanced qualities of denture base, in this paper we investigated the mechanical properties of commercial denture base material modified with dimethyl itaconate (DMI) and di- $n$-butyl itaconate (DBI).

\section{Experimental}

2.1. Materials. The commercial dental resin Biocryl was kindly supplied by Galenika AD, Belgrade, Serbia, and was used as received. The liquid component consists of MMA as monomer and ethylene glycol dimethacrylate as a crosslinker. The powder component consists of prepolymerized beads of PMMA coated with dibenzoyl peroxide as an initiator. In our previous study the powder component of Biocryl has been characterized and its basic physicochemical properties are $M_{n}=1.27 \times 10^{5} \mathrm{~g} \mathrm{~mol}^{-1}, M_{w}=3.82 \times 10^{5} \mathrm{~g} \mathrm{~mol}^{-1}, \mathrm{PI}=3.01$, monomer content $4.3 \mathrm{wt} \%$, and average particle size of $55 \mu \mathrm{m}$ [41]. DMI and itaconic acid were obtained from Fluka. Butyl alcohol, sulphuric acid, and hydroquinone were supplied by Sigma-Aldrich. DMI was purified by conventional method [36]. DBI was synthesized as described previously [42] and characterized by infrared spectroscopy.

2.2. Sample Preparation. The liquid component of the denture base material, Biocryl, was mixed with selected di- $n$ alkyl itaconate. The amounts of DMI and DBI in the mixture were $0,2.5,5.0,7.5$, and $10 \mathrm{wt} \%$, with respect to the total mass of formulation used (Table 1).

The mixed resins were packed into teflon moulds designed to produce a bar specimens measuring $60 \mathrm{~mm} \times$ $12 \mathrm{~mm} \times 3 \mathrm{~mm}$ for the dynamic mechanical thermal analysis (DMTA) measurements and $80 \mathrm{~mm} \times 10 \mathrm{~mm} \times 4 \mathrm{~mm}$ for the tensile (Figure 2) and the impact strength (Figure 3 ) 
TABLE 1: Feed composition of synthesized denture base materials.

\begin{tabular}{lcccc}
\hline \multirow{2}{*}{ Sample } & \multicolumn{4}{c}{ Feed composition, wt\% } \\
& Biocryl, powder & Biocryl, liquid & DMI & DBI \\
\hline PMMA & 66.0 & 34.0 & $/$ & $/$ \\
2.5 DMI & 64.5 & 33.0 & 2.5 & $/$ \\
5.0 DMI & 63.0 & 32.0 & 5.0 & $/$ \\
7.5 DMI & 61.5 & 31.0 & 7.5 & $/$ \\
$10 \mathrm{DMI}$ & 59.5 & 30.5 & 10 & $/$ \\
$2.5 \mathrm{DBI}$ & 65.0 & 32.5 & $/$ & 2.5 \\
$5.0 \mathrm{DBI}$ & 64.0 & 31.0 & $/$ & 5.0 \\
$7.5 \mathrm{DBI}$ & 63.0 & 29.5 & $/$ & 7.5 \\
$10 \mathrm{DBI}$ & 62.5 & 27.5 & $/$ & 10 \\
\hline
\end{tabular}

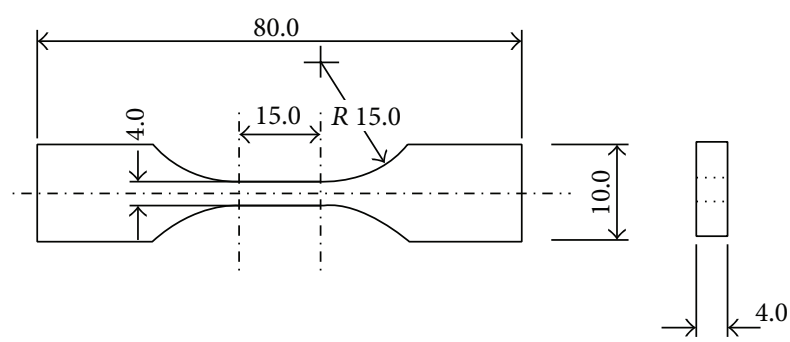

Figure 2: Geometry of the tensile test specimen used in this investigation according to ASTM D882.

measurements. The discs measuring $25 \mathrm{~mm}$ in diameter and $4 \mathrm{~mm}$ thickness were prepared for the hardness measurement. The moulds were then clamped tightly and placed in a thermostatically controlled water bath (NE1B-8, Progen Scientific, London, UK). The denture base acrylic resins were polymerized for 30 minutes at $100^{\circ} \mathrm{C}$ by immersing the moulds into water bath. Specimens were examined visually without magnification and were required to demonstrate no porosity. Five samples were prepared under the same polymerization conditions and were used for all measurements.

The homopolymers of poly(dimethyl itaconate) (PDMI) and poly(di- $n$-butyl itaconate) (PDBI) were prepared at $50^{\circ} \mathrm{C}$ in toluene solution $\left(3 \mathrm{~mol} \mathrm{dm}^{-3}\right)$ using AIBN $(1.5 \times$ $10^{-2} \mathrm{~mol} \mathrm{dm}^{-3}$ ) as initiator.

2.3. Fourier Transform Infrared Spectroscopy (FTIR). The spectra were recorded on Bomen MB 100 Fourier transform infrared spectrometer (FTIR), Hartmann \& Braun, Canada. The $10 \mathrm{mg}$ from each polymerized sample was finely ground with $100 \mathrm{mg}$ of $\mathrm{KBr}$. The mixtures were transferred to the pneumatic pellet-making press and left for three minutes under pressure. The $\mathrm{KBr}$ discs with the polymer sample were placed in the IR cell and the spectrum was recorded. All spectra were obtained from 10 scans at resolution of $4 \mathrm{~cm}^{-1}$.

2.4. Scanning Electron Microscopy (SEM). Representative SEM micrographs were taken from the fractured surfaces. The fractured surfaces were carefully cut from the denture

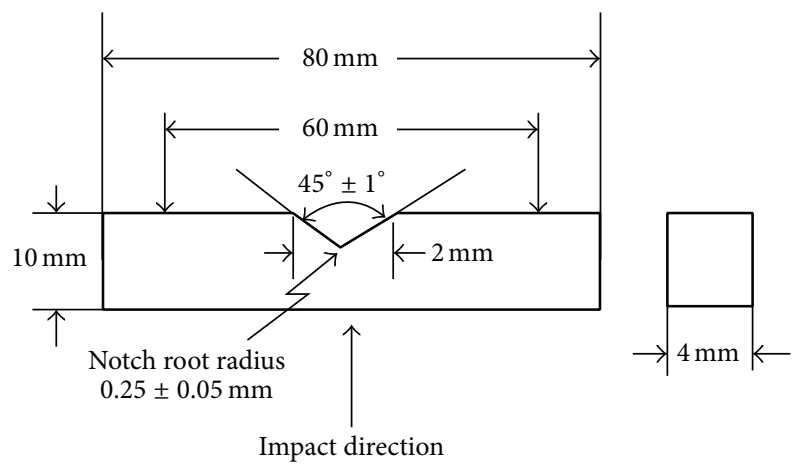

FIGURE 3: Geometry of the Charpy V-notch impact specimen used in this investigation [43].

teeth, stuck to a specimen holder (Plano, Wetzlar, Germany), and sputtered with platinum. SEM evaluation was performed with a scanning electron microscope (type FEI XL30 ESEM FEG, FEI Company, Eindhoven, Netherlands) at an accelerating voltage of $5-10 \mathrm{kV}$.

2.5. Differential Scanning Calorimetry (DSC). The thermal properties of copolymers were studied by differential scanning calorimetry (DSC) using Perkin Elmer DSC-2 thermal analyzer under nitrogen (flow rate $26 \mathrm{~mL} \mathrm{~min}^{-1}$ ). For measurement of the glass transition temperature $\left(T_{g}\right), 10$ $20 \mathrm{mg}$ of sample was placed in an aluminum holder and heated from $50^{\circ} \mathrm{C}$ to $200^{\circ} \mathrm{C}$. The heating rate was set to $20^{\circ} \mathrm{C}$ $\min ^{-1}$. In order to erase the thermal history of the sample all calculations were done using the data acquired from second cycle. The glass transition temperature was estimated as the temperature at midpoint of the line drawn between the temperature of intersection of the initial tangent with the tangent drawn through the point of inflection of the trace and the temperature of intersection of the tangent drawn through the point of inflection with the final tangent.

2.6. Dynamic Mechanical Thermal Analysis (DMTA). Dynamic mechanical thermal analysis tests were performed on a mechanical spectrometer Rheometrics 605 in bending mode. A frequency of $1 \mathrm{~Hz}$ and strain of $0.3 \%$ were applied. A temperature range of $25^{\circ} \mathrm{C}-180^{\circ} \mathrm{C}$ and a heating rate of $3^{\circ} \mathrm{C} \mathrm{min}^{-1}$ were selected to cover mouth temperature and the materials likely glass transition temperature $\left(T_{g}\right)$. Storage modulus $\left(E^{\prime}\right)$, loss modulus $\left(E^{\prime \prime}\right)$, and damping factor $(\tan \delta)$ were plotted against temperature over this period. Glass transition temperatures were recorded as a maximum value of $\tan \delta$.

2.7. Tensile Analysis. Tensile testing was conducted on an Instron Testing Machine (model number 6025) with a clip-on extensometer to measure specimen extension. The employed cross-head speed was $0.5 \mathrm{~mm} \mathrm{~min}^{-1}$, and the maximum force recorded was used to obtain the ultimate tensile strength, $\sigma_{\text {ult }}$. Five specimens were tested, and the standard deviation is reported for all the samples. 


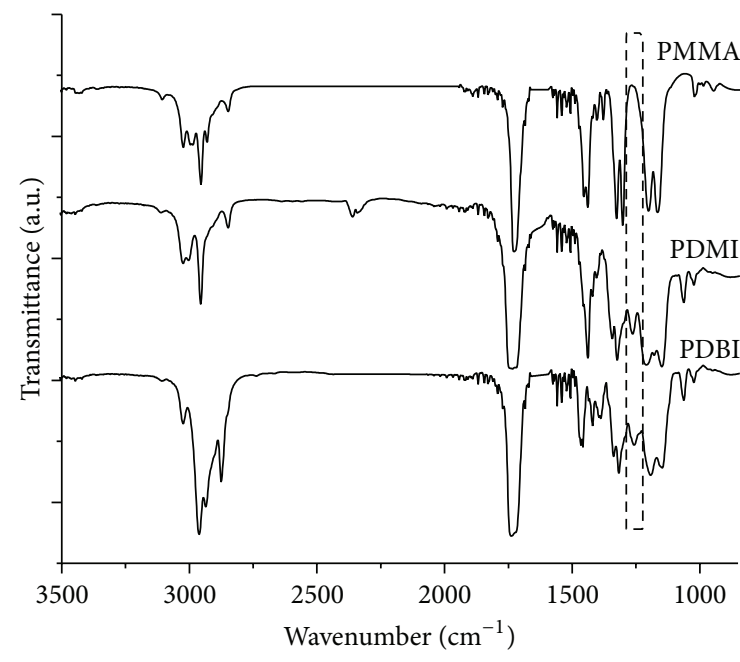

(a)

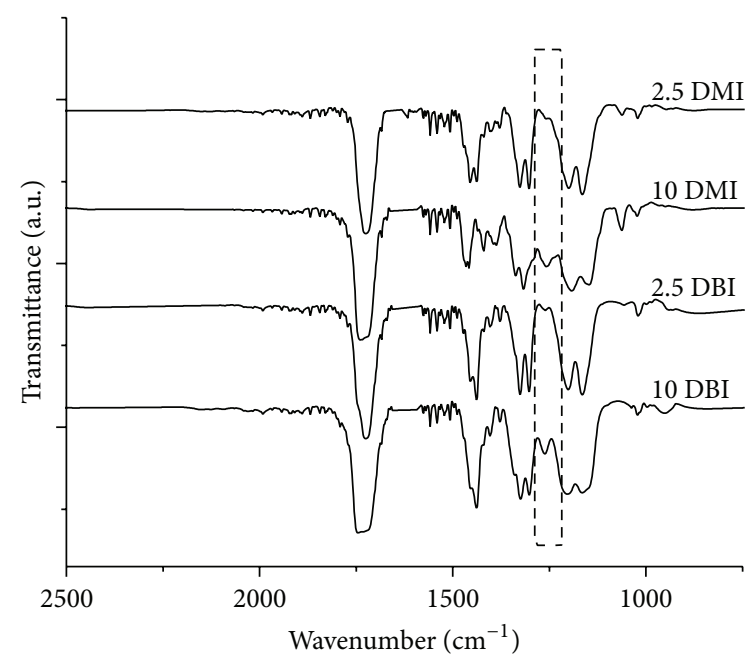

(b)

Figure 4: FTIR spectra of (a) PMMA, PDMI, and PDBI and (b) PMMA denture base materials modified with $2.5 \mathrm{wt} \%$ and $10 \mathrm{wt} \%$ of DMI and DBI.

2.8. Hardness Measurements. Hardness was measured on Instron durometer D-XD (Instron, Norwood). The measurements were taken at 10 measuring points at each sample, and the mean values and standard deviations were calculated.

2.9. Charpy Impact Strength. Charpy impact tests were conducted on a Charpy impact tester using the specimens with a $\mathrm{V}$-notch (Figure 3 ) with the edgewise blow direction. The tests were carried out with striker energy of $8.73 \mathrm{~J}$ and a span length of $60 \mathrm{~mm}$ at $23^{\circ} \mathrm{C}$. The average values of notched Charpy impact energy were obtained from each group of five samples.

\section{Results and Discussion}

This study evaluates the possibility of using itaconates, renewable, nonpetrochemical materials, as cocomponents for the synthesis of denture base materials. Two esters of itaconic acid (DMI and DBI) were used and four samples $(2.5 ; 5.0 ; 7.5$; and $10 \mathrm{wt} \%)$ of denture base materials modified with each of these esters of itaconic acid were prepared. The synthesized samples of PMMA denture base materials modified with DMI and DBI, as well as the homopolymers of PMMA, PDMI, and PDBI, were characterized by FTIR analysis. Figure 4(a) shows FTIR spectra of PMMA, PDMI, and PDBI, while Figure 4(b) shows FTIR spectra of PMMA denture base materials modified with $2.5 \mathrm{wt} \%$ and $10 \mathrm{wt} \%$ of $\mathrm{DMI}$, that is, DBI.

FTIR spectra of PMMA, PDMI, and PDBI are very similar, as shown in Figure 4(a). Each spectrum shows a sharp intense peak at $1731 \mathrm{~cm}^{-1}$, which is attributed to the presence of $\mathrm{C}=\mathrm{O}$ stretching vibrations. The broad peak ranging from $1260 \mathrm{~cm}^{-1}$ to $1000 \mathrm{~cm}^{-1}$ is due to $\mathrm{C}-\mathrm{O}$ (ester bond) stretching vibrations. The broad band from $950 \mathrm{~cm}^{-1}$ to $650 \mathrm{~cm}^{-1}$ is due to $\mathrm{C}-\mathrm{H}$ bending. The peaks at $3025 \mathrm{~cm}^{-1}$, $2950 \mathrm{~cm}^{-1}$, and $2845 \mathrm{~cm}^{-1}$ are due to the presence of $\mathrm{C}-\mathrm{H}$ stretching vibrations. In spite of being very similar, some subtle differences between FTIR spectrum of PMMA and itaconates are observed because of the presence of the second ester group in itaconates. The peak at $1266 \mathrm{~cm}^{-1}(\mathrm{C}-\mathrm{O}-\mathrm{C}$ asymmetric stretching vibration) is presented in PDMI and PDBI FTIR spectra, while for PMMA this band is shifted to lower wave numbers. The increase in itaconate content in denture base material leads to the increase in the intensity of peak at $1266 \mathrm{~cm}^{-1}$ (Figure 4(b)).

Figures 5(a) and 5(b) show the DSC thermograms of the initial PMMA denture base material and PMMA denture base material modified with DMI (a) and DBI (b).

The initial PMMA denture base material shows single $T_{g}$ around $123^{\circ} \mathrm{C}$. Single $T_{g}$ is also observed with the PMMA denture base materials modified with itaconates (Table 2), which indicates that these copolymers are homogeneous in the range of $10-30 \mathrm{~nm}$ [44]. The difference between the chemical structures of MMA and DMI is that the one hydrogen of the $\alpha$-methyl group is replaced by a $-\mathrm{COOCH}_{3}$ group. It can be seen from the data presented in Table 2 that this substitution caused the lowering of $T_{g}$ presumably owing to the plasticizing effect of the additional flexible ester group. The insertion of methylene units to lengthen the ester side chains increases their flexibility and leads to internal plasticization of the polymer. This results in a progressive decrease in $T_{g}$ as the side chains lengthen, so, decrease in $T_{g}$ was more pronounced in samples modified with DBI than DMI (Table 2).

The values of storage modulus $\left(E^{\prime}\right)$, loss modulus $\left(E^{\prime \prime}\right)$ at $37^{\circ} \mathrm{C}$, damping factor $(\tan \delta)$, and glass transition temperatures calculated from DSC $\left(T_{g, \text { DSC }}\right)$ and DMTA $\left(T_{g, \text { DMTA }}\right)$ measurements for PMMA denture base materials modified with DMI and DBI, are listed in Table 2. The obtained results for $T_{g}$ indicated that the $T_{g}$ values derived from the maximum of the dependence $\tan \delta$ versus temperature. That is, DMTA are higher than those obtained by DSC. Although the values 


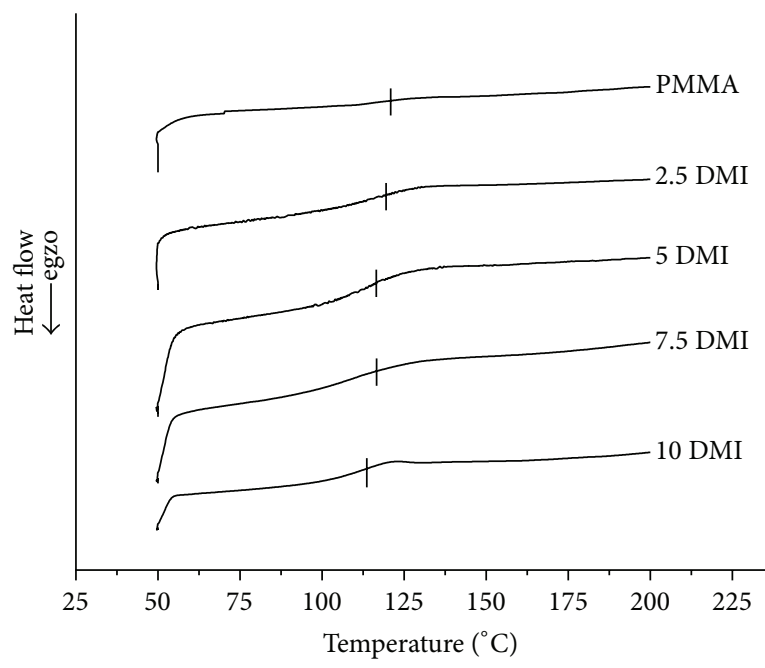

(a)

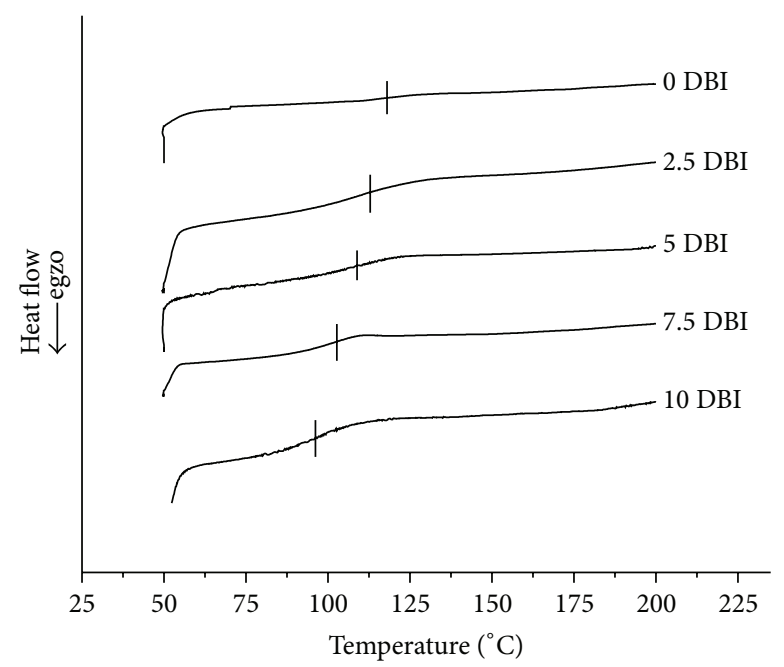

(b)

FIgURE 5: DSC curves of PMMA denture base materials modified with (a) DMI and (b) DBI.

TABLE 2: Storage modulus $\left(E^{\prime}\right)$, loss modulus $\left(E^{\prime \prime}\right)$ and damping factor $\left(\tan \delta_{37}\right)$ at $37^{\circ} \mathrm{C}$, maximal value for damping factor (tan $\delta$ ), and glass transition temperatures obtained by DSC $\left(T_{g, \text { DSC }}\right)$ and DMTA $\left(T_{g, \text { DMTA }}\right)$ measurements for PMMA denture base materials modified with DMI and DBI.

\begin{tabular}{|c|c|c|c|c|c|c|}
\hline Sample & $E^{\prime}, \mathrm{GPa}$ & $E^{\prime \prime}, \mathrm{MPa}$ & $\tan \delta_{37}$ & $\tan \delta_{\max }$ & $T_{g, \mathrm{DSC}},{ }^{\circ} \mathrm{C}$ & $T_{g, \text { DMTA }},{ }^{\circ} \mathrm{C}$ \\
\hline PMMA & 4.03 & 359 & 0.089 & 1.31 & 123.2 & 141.5 \\
\hline $2.5 \mathrm{DMI}$ & 3.99 & 375 & 0.094 & 1.34 & 122.5 & 139.1 \\
\hline 5.0 DMI & 3.83 & 440 & 0.115 & 1.46 & 121.1 & 136.2 \\
\hline $7.5 \mathrm{DMI}$ & 3.65 & 464 & 0.127 & 1.52 & 119.7 & 134.5 \\
\hline $10 \mathrm{DMI}$ & 3.41 & 481 & 0.141 & 1.65 & 117.5 & 133.5 \\
\hline $2.5 \mathrm{DBI}$ & 3.86 & 417 & 0.108 & 1.41 & 111.0 & 127.9 \\
\hline $5.0 \mathrm{DBI}$ & 3.71 & 460 & 0.124 & 1.53 & 106.4 & 123.7 \\
\hline $7.5 \mathrm{DBI}$ & 3.47 & 475 & 0.137 & 1.63 & 103.8 & 117.3 \\
\hline $10 \mathrm{DBI}$ & 3.13 & 513 & 0.164 & 1.81 & 93.4 & 107.4 \\
\hline
\end{tabular}

of $T_{g, \text { DMTA }}$ are higher than those of $T_{g, \text { DSC }}$, the trend of $T_{g}$ variation is similar for both methods.

Figures 6(a) and 6(b) show the effect of copolymer composition on storage modulus $\left(E^{\prime}\right)$ dependence over temperature.

An "ideal" hard denture reline material would demonstrate a high stiffness $\left(E^{\prime}\right)$ and a moderate deformation with stress $\left(E^{\prime \prime}\right)$ but a low $\tan \delta$, as it is preferable that the material returns to its original shape shortly after the load is removed. As presented in Figures 6(a) and 6(b), between $25^{\circ} \mathrm{C}$ and $100^{\circ} \mathrm{C}$, the modified denture base materials behaved as a homogeneous rigid solids, while the increase in temperature was firstly followed by a dramatic fall in modulus over a short temperature span when the material became rubbery beyond its $T_{g}$ and afterwards $E^{\prime}$ entry into the plateau. It is also clear that the storage modulus decreased with increasing itaconate concentration while at the same time loss modulus and $\tan \delta$ increased as could be seen from their values presented in Table 2 . The presented values are obtained at $37^{\circ} \mathrm{C}$ because that is the material's operational temperature. These results indicated that the addition of itaconates in PMMA denture base material reduced material's stiffness and increased its deformation with stress due to the plasticizing effect of the aliphatic side chains of itaconates. The decrease in $E^{\prime}$ and increase in $E^{\prime \prime}$ and $\tan \delta$ were more pronounced in case of DBI compared to DMI which further confirmed the previous statements. However, we can note that, in case of addition of a small amount of DMI (2.5 wt\%) the decrease in $E^{\prime}$ was negligible (less than $1 \%$ ) which means that with this amount of itaconate, the denture base material had practically the same dynamic-mechanical properties as the commercial material. The $T_{g}$ values obtained by DMTA measurements (i.e., temperature corresponding to $\tan \delta$ maximum) are higher compared to the $T_{g}$ values measured by DSC (Table 2) which is in accordance with the literature data [45]. The $T_{g}$ obtained by DSC method represents the temperature at which the material undergoes the maximum change in polymer chain mobility that corresponds to the chemical definition of the $T_{g}$. The $T_{g}$ obtained as peak of the $\tan \delta$ dependence over temperature describes the damping characteristics of material and has historical significance, since it was the first DMTA property quantified and much 


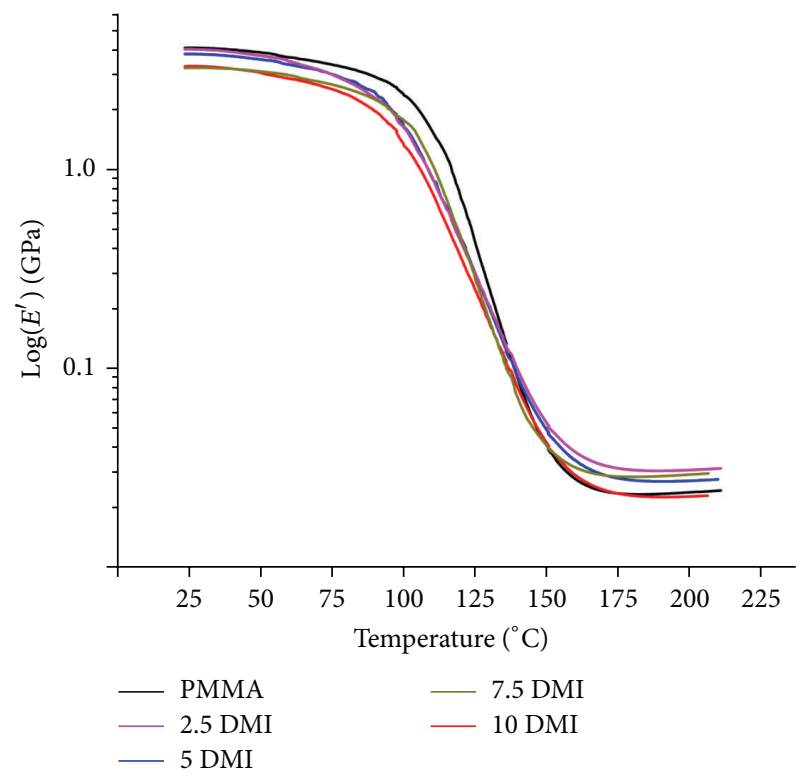

(a)

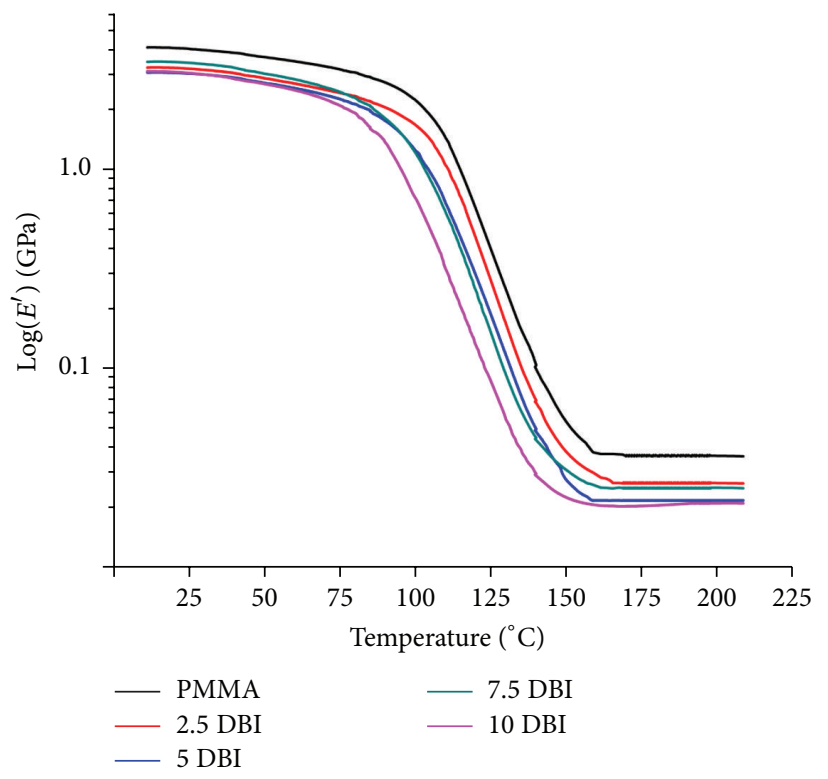

(b)

FIgURE 6: Changes in storage modulus $\left(E^{\prime}\right)$ over temperature for PMMA denture base materials modified with (a) DMI and (b) DBI.

TABLE 3: Ultimate tensile strength $\left(\sigma_{\text {ult }}\right)$, elongation at break $(\varepsilon)$, Shore D hardness, and Charpy impact strength of PMMA denture base materials modified with DMI and DBI.

\begin{tabular}{lcccc}
\hline Sample & $\sigma_{\text {ult }}, \mathrm{MPa}$ & $\varepsilon$ & Shore D & Charpy, $/ \mathrm{cm}^{2}$ \\
\hline PMMA & 63.8 & 6.18 & 96.0 & 0.315 \\
2.5 DMI & 61.8 & 5.21 & 96.3 & 0.317 \\
5.0 DMI & 58.1 & 4.91 & 97.0 & 0.307 \\
7.5 DMI & 55.8 & 4.43 & 96.1 & 0.301 \\
$10 \mathrm{DMI}$ & 52.7 & 5.08 & 94.9 & 0.294 \\
2.5 DBI & 58.5 & 5.23 & 91.5 & 0.309 \\
$5.0 \mathrm{DBI}$ & 56.3 & 4.7 & 95.5 & 0.295 \\
7.5 DBI & 54.9 & 4.71 & 94.8 & 0.281 \\
10 DBI & 54.2 & 6.26 & 95.1 & 0.268 \\
\hline
\end{tabular}

of the DMTA $T_{g}$ reference data is based on the $\tan \delta$ peak temperature.

The obtained results for ultimate tensile strength $\left(\sigma_{\mathrm{ult}}\right)$, elongation at break $(\varepsilon)$, Shore D hardness, and Charpy impact strength are presented in Table 3.

The tensile behavior of PMMA denture base materials modified with DMI or DBI is presented in Table 3. The materials modified with itaconates, especially those containing DBI, exhibited a lower ultimate tensile strength compared to the commercial PMMA denture base material, suggesting that the incorporation of aliphatic side chain into methacrylates structure decreased the strength of the material. A plausible explanation for this behavior rests on the fact that mechanical properties depend on the morphology of the material. The introduction of bulky pendant group hinders the ideal lining up of the polymer chains producing microdefects in the polymeric structure that result in decrease in ultimate tensile strength. The reduction of ultimate tensile strength increased with the increase in itaconate content in the system as well as with the increase in the side chain length which furthermore confirmed the findings stated above. However, bearing in mind the advantages of using of itaconates over methacrylates and the fact that the prescribed tensile strength requirements [46] were attained, it could be concluded that, regarding investigated parameter, denture base materials modified with itaconates are suitable replacements for commercial, pure PMMA material.

Table 3 also shows elongation at break and the mean Shore D hardness of the PMMA denture base materials modified with DMI and DBI.

The increase in itaconate content led to the decrease in elongation at break except for the samples modified with $10 \mathrm{wt} \%$ of itaconates in which case elongation increased.

Even though there were some differences between the hardness values of the different samples, these differences were too small to be relevant. Taking into consideration all the factors that affect the hardness of material (surface porosity, residual monomer concentration, etc.) we may presume that the modification of PMMA denture base material had no effect on Shore D hardness. All investigated materials fulfilled the required hardness values for denture base materials [46].

In all impact tests experiments, the specimens broke with a sharp fracture, exhibiting a typical brittle fracture behavior characterized by a lack of distortion of the broken parts. There was a significant difference between the impact resistance of the control and samples modified with $7.5 \mathrm{wt} \%$ and $10 \mathrm{wt} \%$ of DBI. The lower impact resistance of these modified materials may be attributed to the formation of microdefects in the polymer matrix which were formed as a result of the introduction of linear side chain. These microdefects act as a stress concentrator and crack accelerator. Despite the 


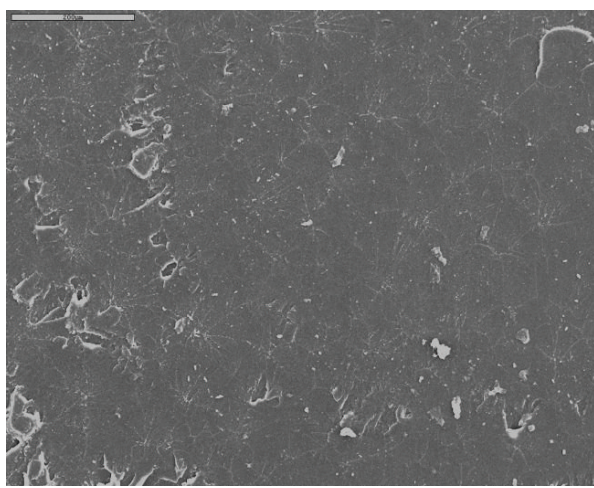

(a)

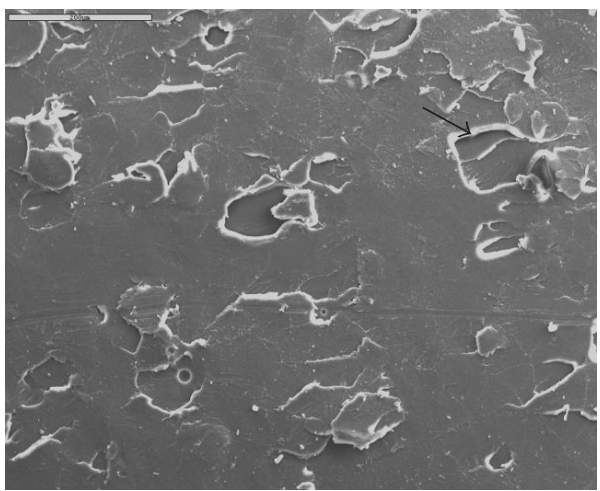

(c)

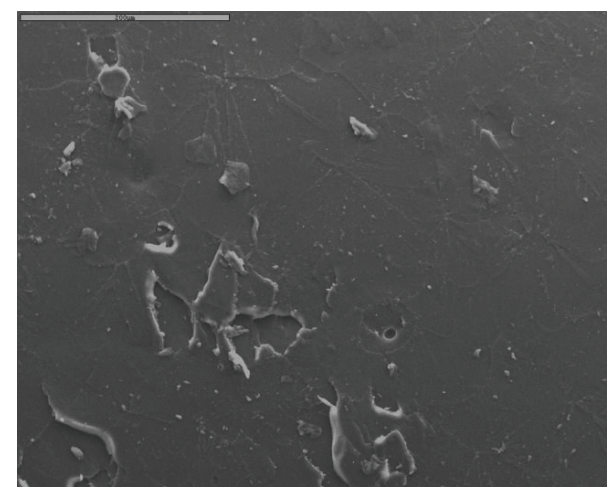

(b)

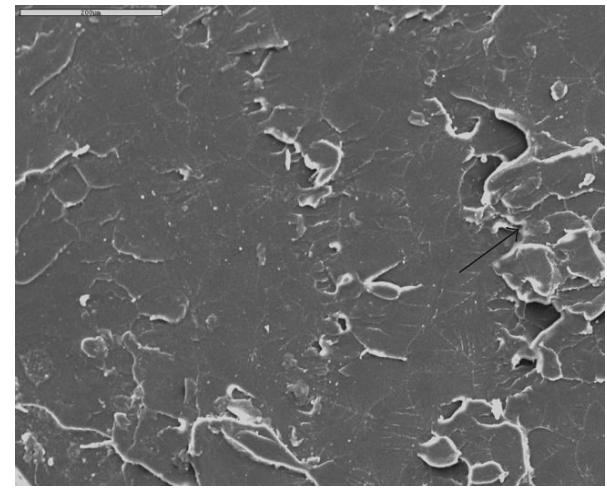

(d)

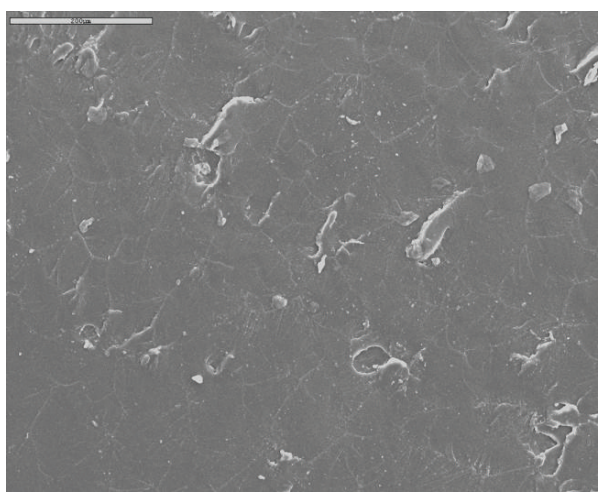

(e)

FiguRE 7: SEM images of brittle fractures of PMMA denture base material modified with (a) $2.5 \mathrm{wt} \%$ of DMI, (b) $2.5 \mathrm{wt} \%$ of DBI, (c) $10 \mathrm{wt} \%$ of DMI, (d) $10 \mathrm{wt} \%$ of DBI, and (e) commercial PMMA denture base material (original magnification 200 times).

progressive reduction in impact resistance with the increase in itaconates amount (Table 3), the measured impact energy values satisfied the requirements of the American Dental Standards Institute [46].

The SEM images of fractures of PMMA denture base material modified with DMI and DBI are presented in Figure 7. The fractures that exhibited a smooth surface were classified as brittle. Those presenting plastic deformations, exhibiting rough and jagged surfaces, were recorded as intermediate (ductile-to-brittle transition) fractures.

The SEM microscopy showed that most fractures were brittle for the denture base materials modified with low amount of itaconates. The brittle fractures exhibited well-defined, flat, compact, and organized surface fractures. However, fractures of samples modified with 10 weight percent of itaconates presented higher amount of irregular surface patterns (Figures $7(\mathrm{c})$ and $7(\mathrm{~d})$ ) when compared to the other samples (Figures 7(a), 7(b), and 7(e)), with a high number of grooves in the brittle fractures and presence of crazing in the intermediate fractures. Arrows in Figures $7(\mathrm{c})$ and $7(\mathrm{~d})$ show the presence of crazing, revealing high plastic deformation. Although irregularities could be seen in each fracture of examined samples, a common finding was that a granular microstructure was clearly distinguishable, demonstrating that acrylic resin fails by transgranular or transcrystalline fracture [47]. 


\section{Conclusions}

This study evaluated the possibility of using itaconates, renewable, nonpetrochemical materials, as cocomponents in the synthesis of denture base materials. Two esters of itaconic acid (DMI and DBI) were used in four concentrations (2.5; 5.0; 7.5; and $10 \mathrm{wt} \%$ ) to modify the commercial denture base materials. The blending of itaconates with other components was homogenous and confirmed by FTIR analysis. Also the DSC analysis showed progressive decrease in $T_{g}$ values with the increase in itaconate component amount, compared to $T_{g}$ of the pure PMMA formulation, and, by showing one $T_{g}$ value for all samples, confirmed their homogeneity. The plasticizing effect of itaconates was observed and confirmed with the decrease in $E^{\prime}$ and $E^{\prime \prime}$ and the ultimate tensile strength values. This effect was more pronounced when the itaconate with longer aliphatic chain, DBI, was used. With the increasing amount of itaconates, except for the $10 \mathrm{DBI}$ sample, the elongation at break was increased. All employed measurements confirmed that required values of mechanical properties for denture base materials were fulfilled. This investigation showed that modification of PMMA denture base materials with alkyl itaconates was a feasible way to obtain materials that were more environmentally and patient friendly than pure PMMA denture base materials.

\section{Conflict of Interests}

The authors declare that there is no conflict of interests regarding the publication of this paper.

\section{Acknowledgments}

The authors would like to acknowledge funding from the Ministry of Education, Science and Technological Development of the Republic of Serbia, through Project no. 172062 "Synthesis and characterization of novel functional polymers and polymeric nanocomposites."

\section{References}

[1] S. Cooper, S. Visser, R. Hergenrother, and N. Lamba, "Polymers," in Biomaterials Science: An Introduction to Materials in Medicine, B. Ratner, A. Hoffman, and F. Schoen, Eds., pp. 6780, Elsevier Academic Press, San Diego, Calif, USA, 2nd edition, 2004.

[2] A. Palitsch, M. Hannig, P. Ferger, and M. Balkenhol, "Bonding of acrylic denture teeth to MMA/PMMA and light-curing denture base materials: the role of conditioning liquids," Journal of Dentistry, vol. 40, no. 3, pp. 210-221, 2012.

[3] J. K. Anusavice, Phillip's Science of Dental Materials, WB Saunders, Philadelphia, Pa, USA, 2003.

[4] F. Bayindir, D. Kurklu, and N. D. Yanikoglu, "The effect of staining solutions on the color stability of provisional prosthodontic materials," Journal of Dentistry, vol. 40, no. 2, pp. e41-e46, 2012.

[5] D. Nagao, T. Kinoshita, A. Watanabe, and M. Konno, "Fabrication of highly refractive, transparent $\mathrm{BaTiO}_{3} /$ poly(methyl methacrylate) composite films with high permittivities," Polymer International, vol. 60, no. 8, pp. 1180-1184, 2011.
[6] E. Rubio, J. Almaral, R. Ramírez-Bon, V. Castaño, and V. Rodríguez, "Organic-inorganic hybrid coating (poly(methyl methacrylate)/monodisperse silica)," Optical Materials, vol. 27, no. 7, pp. 1266-1269, 2005.

[7] J. A. Reglero Ruiz, C. Saiz-Arroyo, M. Dumon, M. A. RodríguezPerez, and L. Gonzalez, "Production, cellular structure and thermal conductivity of microcellular (methyl methacrylate)(butyl acrylate)-(methyl methacrylate) triblock copolymers," Polymer International, vol. 60, no. 1, pp. 146-152, 2011.

[8] M. I. Shtilman, Polymeric Biomaterials, VSP BV, Utrecht, The Netherlands, 2003.

[9] K. Kuhn, "What is bone cement?" in The Well-Cemented Total Hip Arthroplasty: Theory and Practice, S. Breusch and $\mathrm{H}$. Malchau, Eds., pp. 52-60, Springer Medizin, Heidelberg, Germany, 2005.

[10] P. M. Preshaw, A. W. G. Walls, N. S. Jakubovics, P. J. Moynihan, N. J. A. Jepson, and Z. Loewy, "Association of removable partial denture use with oral and systemic health," Journal of Dentistry, vol. 39, no. 11, pp. 711-719, 2011.

[11] C. Bural, E. Aktaş, G. Deniz, Y. Ünlüçerçi, N. Kızılcan, and G. Bayraktar, "Effect of post-polymerization heat-treatments on degree of conversion, leaching residual MMA and in vitro cytotoxicity of autopolymerizing acrylic repair resin," Dental Materials, vol. 27, no. 11, pp. 1135-1143, 2011.

[12] G. Kansu, T. Kalyoncuoğlu, P. Uyar, and E. Uzun, "Cell death induced by eluates from hypoallergenic denture base acrylic resins in NIH-3T3 fibroblast cells," Journal of Dental Sciences, vol. 9, pp. 381-387, 2014.

[13] B. Axelsson and G. Nyquist, "The leaching and biological effect of the residual monomer of methyl methacrylate," Odontologisk Revy, vol. 27, pp. 370-379, 1962.

[14] J. F. McCabe and R. M. Basker, "Tissue sensitivity to acrylic resin. A method of measuring the residual monomer content and its clinical application," British Dental Journal, vol. 140, no. 10, pp. 347-350, 1976.

[15] C. De Andrade Lima Chaves, A. L. Machado, C. E. Vergani, R. F. De Souza, and E. T. Giampaolo, "Cytotoxicity of denture base and hard chairside reline materials: a systematic review," Journal of Prosthetic Dentistry, vol. 107, no. 2, pp. 114-127, 2012.

[16] D. C. Smith, "The acrylic denture base-mechanical evaluation of dental poly(methylmethacrylate)," British Dental Journal, vol. 111, pp. 9-17, 1961.

[17] T. Kobayashi, "Production of itaconic acid from wood waste," Process Biochemistry, vol. 5, pp. 15-22, 1978.

[18] E. Riscaldati, M. Moresi, F. Federici, and M. Petruccioli, "Effect of $\mathrm{pH}$ and stirring rate on itaconate production by Aspergillus terreus," Journal of Biotechnology, vol. 83, no. 3, pp. 219-230, 2000.

[19] Japan Chemical Industry Ecology-Toxicology and Information Center, SIDS Initial Assesment Profile CAS No. 97-65-4, Japan Chemical Industry Ecology-Toxicology and Information Center, Tokyo, Japan, 2001.

[20] M. V. Bernardo, M. D. Blanco, R. Olmo, and J. M. Teijón, "Delivery of bupivacaine included in poly(acrylamide-comonomethyl itaconate) hydrogels as a function of the $\mathrm{pH}$ swelling medium," Journal of Applied Polymer Science, vol. 86, no. 2, pp. 327-334, 2002.

[21] M. D. Blanco, M. V. Bernardo, C. Teijón, R. L. Sastre, and J. M. Teijón, "Transdermal application of bupivacaine-loaded poly(acrylamide(A)-co-monomethyl itaconate) hydrogels," International Journal of Pharmaceutics, vol. 255, no. 1-2, pp. 99107, 2003. 
[22] M. D. Blanco, O. García, R. M. Trigo, J. M. Teijón, and I. Katime, "5-Fluorouracil release from copolymeric hydrogels of itaconic acid monoester: I. Acrylamide-co-monomethyl itaconate," Biomaterials, vol. 17, no. 11, pp. 1061-1067, 1996.

[23] S. K. Bajpai and J. Sonkusley, "Dynamic release of riboflavin from a colon-targeted delivery device: an in vitro study," Reactive and Functional Polymers, vol. 55, no. 2, pp. 197-210, 2003.

[24] N. B. Milosavljević, N. Z. Milašinović, I. G. Popović, J. M. Filipović, and M. T. Kalagasidis Krušić, "Preparation and characterization of $\mathrm{pH}$-sensitive hydrogels based on chitosan, itaconic acid and methacrylic acid," Polymer International, vol. 60, no. 3, pp. 443-452, 2011.

[25] M. Nakamura and T. Inoue, "Coating material and molded article," United States Patent 6,759,473, 2004.

[26] G. R. Larson, L. J. Procopio, W. J. Rosano, and O. C. Ziemann, "Binder compositions for direct-to-metal coatings," United States Patent 6,756,459, 2004.

[27] W. Bremser, "Base coat and its use for producing color and/or effect-producing base coatings and multi-layer coatings," United States Patent 6,737,468, 2004.

[28] K. Sato and K. Kodama, "Positive-working resist composition," United States Patent 6,777,160, 2004.

[29] K. Shirakawa, Y. Adegawa, and S. Yasunami, "Negative resist composition," US Patent no. 6,773,862, 2004.

[30] A. Berube and C. Lapalme, "Multi-focal contact lens," United States patent 6,733,125, 2004.

[31] T. Watanabe, E. Ito, S. Tanikawa, S. Ichinohe, T. Yamazaki, and M. Lamrani, "Process for preparing ocular lens with urethane compound and process for preparing urethane compound for medical instruments," United States Patent 6,770,728, 2004.

[32] E. R. Lukenbach, C. Kaminski, S. Pascal-Suisse, M. Tahar, and M. Ruggiero, "Personal care compositions comprising liquid ester mixtures," US Patent no. 6,762,158, 2004.

[33] A. Moshaverinia, N. Roohpour, S. Ansari et al., "Effects of Nvinylpyrrolidone (NVP) containing polyelectrolytes on surface properties of conventional glass-ionomer cements (GIC)," Dental Materials, vol. 25, no. 10, pp. 1240-1247, 2009.

[34] W. Wu, D. Xie, A. Puckett, and J. W. Mays, "Synthesis of amino acid-containing polyacids and their application in self-cured glass-ionomer cement," European Polymer Journal, vol. 39, no. 5, pp. 959-968, 2003.

[35] A. Moshaverinia, S. Ansari, Z. Movasaghi, R. W. Billington, J. A. Darr, and I. U. Rehman, "Modification of conventional glassionomer cements with $\mathrm{N}$-vinylpyrrolidone containing polyacids, nano-hydroxy and fluoroapatite to improve mechanical properties," Dental Materials, vol. 24, no. 10, pp. 1381-1390, 2008.

[36] M. Fernández-García, E. L. Madruga, and R. CuervoRodríguez, "A kinetic study on the radical copolymerization of dimethyl itaconate and methyl methacrylate in benzene," Polymer, vol. 37, no. 2, pp. 263-268, 1996.

[37] E. L. Madruga and M. Fernández-García, "Free-radical homopolymerization and copolymerization of di-n-butyl itaconate," Polymer, vol. 35, no. 20, pp. 4437-4442, 1994.

[38] M. Fernández-García and E. L. Madruga, "Glass transitions in dimethyl and di-n-butyl poly(itaconate ester)s and their copolymers with methyl methacrylate," Polymer, vol. 38, no. 6, pp. 1367-1371, 1997.

[39] M. Fernández-Garcia, J. L. de la Fuente, and E. L. Madruga, "Thermal behavior of poly(dimethyl itaconate) and poly(din-butyl itaconate) copolymerized with methyl methacrylate," Polymer Engineering and Science, vol. 41, no. 9, pp. 1616-1625, 2001.
[40] P. Spasojević, D. Stamenković, R. Pjanović et al., "Diffusion and solubility of commercial poly(methyl methacrylate) denture base material modified with dimethyl itaconate and di-n-butyl itaconate during water absorption/desorption cycles," Polymer International, vol. 61, no. 8, pp. 1272-1278, 2012.

[41] P. Spasojević, B. Adnadević, S. Veličković, and J. Jovanović, "Influence of microwave heating on the polymerization kinetics and application properties of the PMMA dental materials," Journal of Applied Polymer Science, vol. 119, no. 6, pp. 3598-3606, 2011.

[42] J. Veličković and S. Vasović, "KUHN-MARK-HOUWINKSAKURADA relations and unperturbed dimensions of poly(din-alkyl itaconates)," Die Makromolekulare Chemie, vol. 153, no. 1, pp. 207-218, 1972.

[43] S. Y. Fu, B. Lauke, E. Mäder, X. Hu, and C. Y. Yue, "Fracture resistance of short-glass-fiber-reinforced and short-carbonfiber-reinforced polypropylene under Charpy impact load and its dependence on processing," Journal of Materials Processing Technology, vol. 89-90, pp. 501-507, 1999.

[44] L. A. Utracki, Polymer Alloy and Blends, Hanser Publishers, Munich, Germany, 1989.

[45] R. F. Chartoff, P. T. Weissman, and A. Sircar, "The application of dynamic mechanical methods to $\mathrm{T}_{\mathrm{g}}$ determination in polymers: an overview," in Assignment of the Glass Transition, R. J. Sayler, Ed., pp. 88-108, American Society for Testing and Materials, Philadelphia, Pa, USA, 1994.

[46] ADA, American Dental Standers Institute/American Dental Association Specification No 12 for Denture Base Polymer Chicago Councilor Dental Materials and Devices, American Dental Association, Chicago, Ill, USA, 2002.

[47] R. P. Kusy and D. T. Turner, "Fractography of poly(methyl methacrylates)," Journal of Biomedical Materials Research, vol. 9, no. 4, pp. 89-98, 1975. 

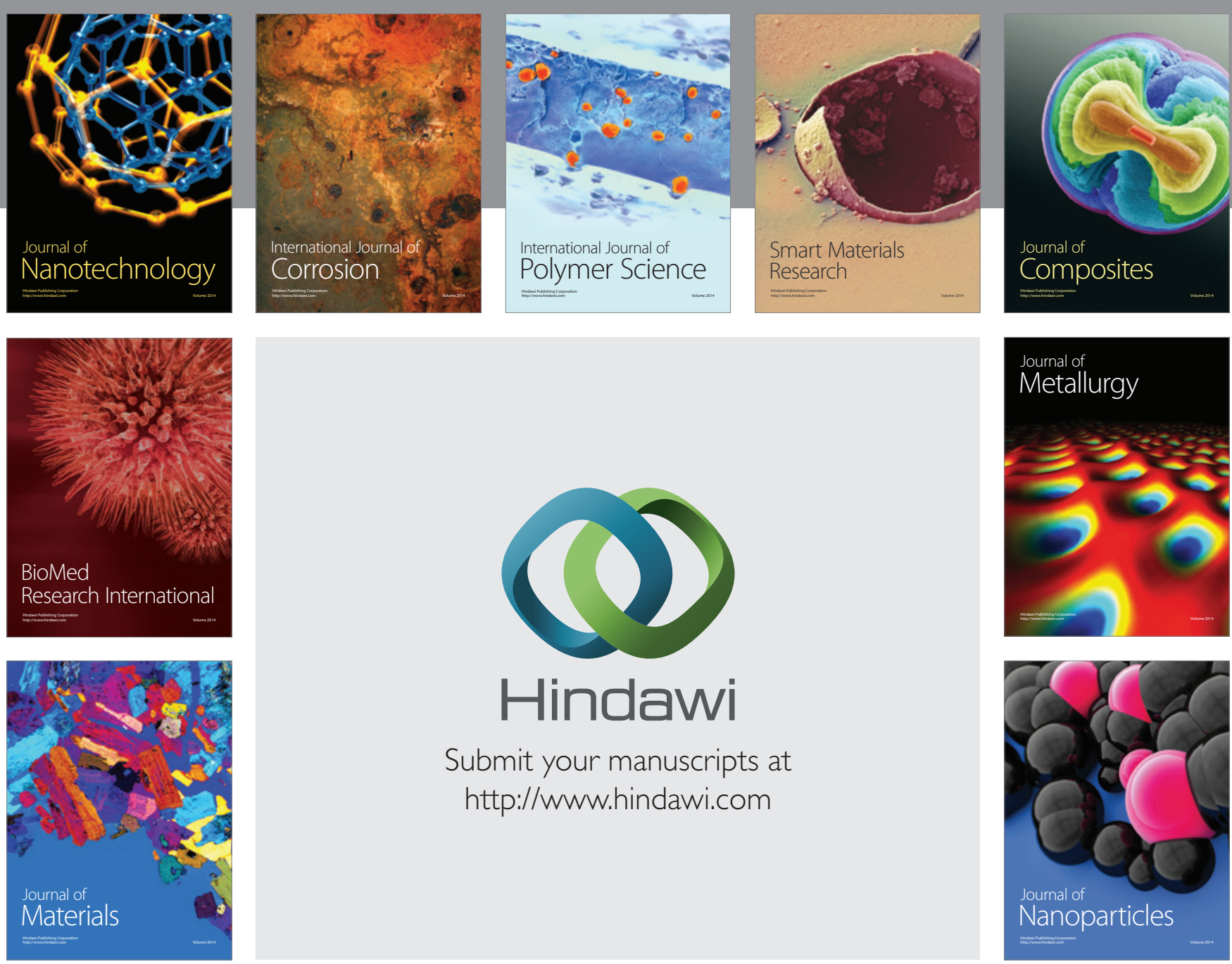

Submit your manuscripts at http://www.hindawi.com
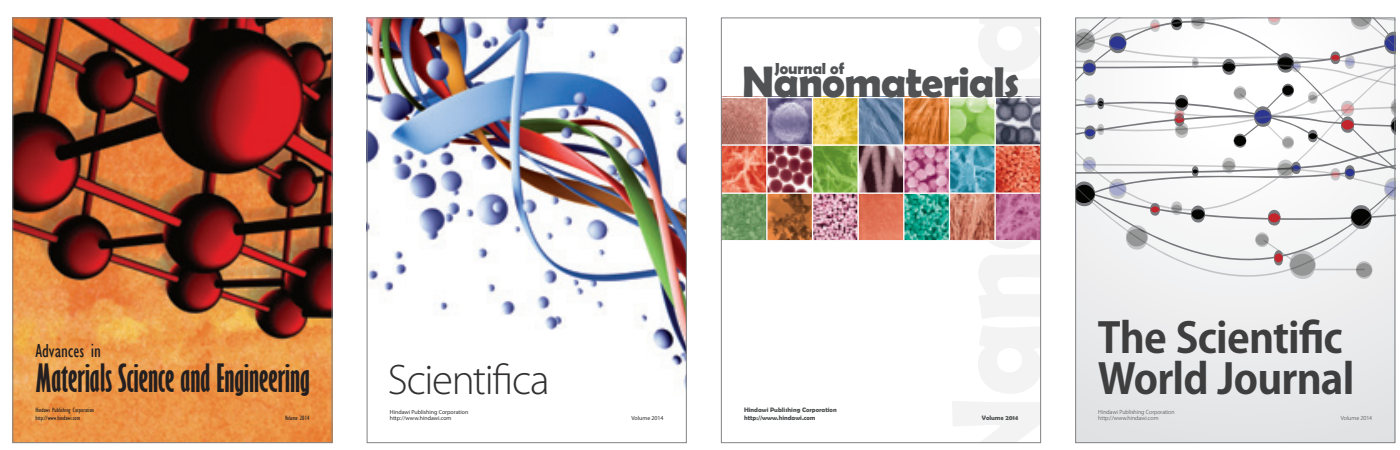

\section{The Scientific World Journal}
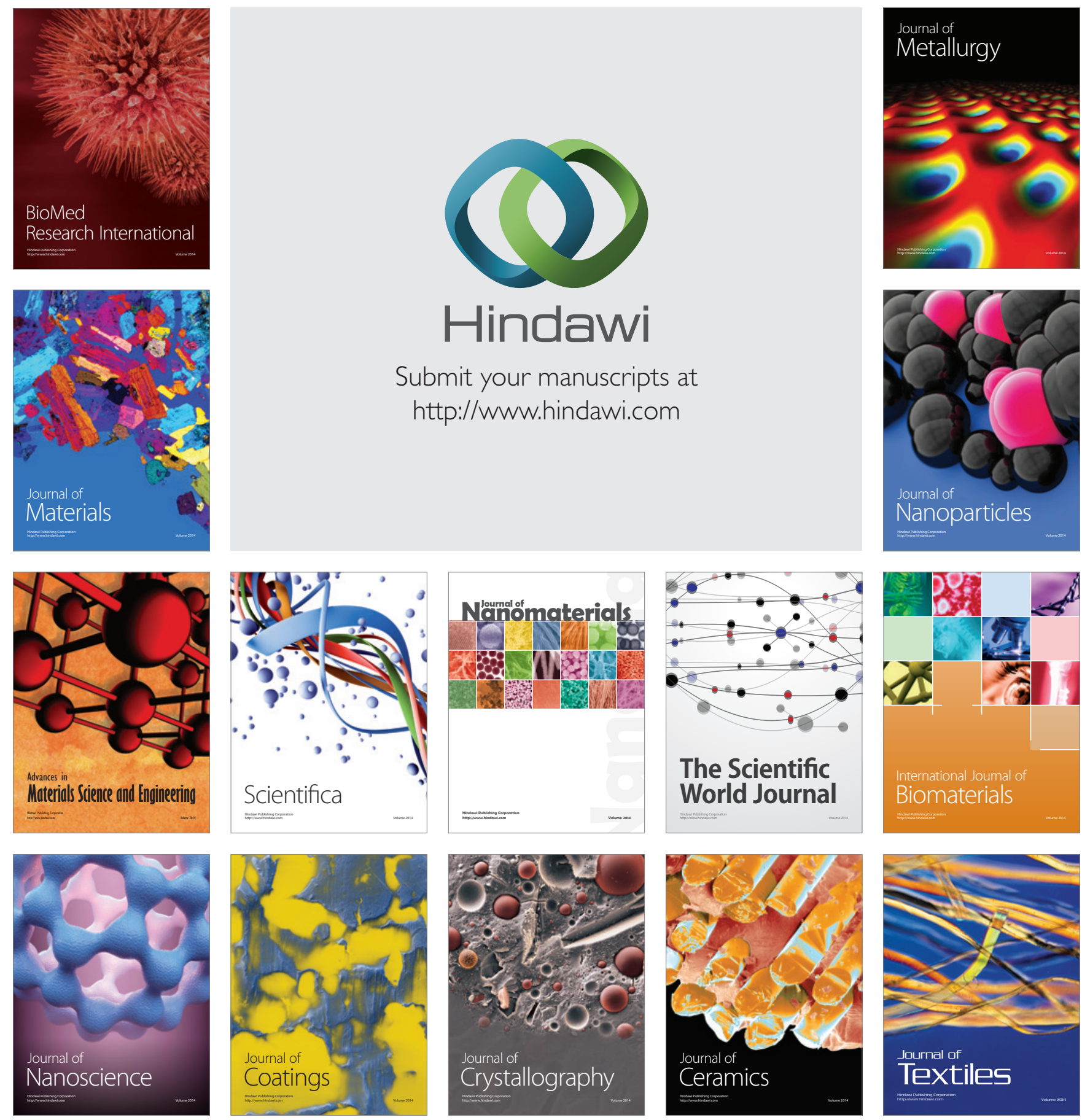